CHAPTER 1:

\title{
Introduction to the IEA International Computer and Information Literacy Study 2018
}

\section{Background}

The International Association for the Evaluation of Educational Achievement (IEA) has been researching the impact of information and communications technologies (ICT) on educational processes, and factors supporting or impeding the pedagogical use of ICT, since the late-1980s. More recently it has turned its attention to investigating ICT-related educational outcomes. IEA's International Computer and Information Literacy Study (ICILS) was developed in response to the increasing use of ICT in modern society and the need for people to have the capabilities necessary to participate effectively in a digital world.

The first cycle of ICILS in 2013 (ICILS 2013) assessed students' computer and information literacy (CIL) which brings together technical competence with computer applications and the capacity to manage information (Fraillon et al. 2014). This places an emphasis on the use of computers as information seeking, management, and communication tools which are key to participation in the digital age (see, for example, Chalkiadaki 2018; van Laar et al. 2017).

This second cycle of ICILS in 2018 (ICILS 2018) continued to investigate students' CIL but also investigated students' computational thinking (CT). This dimension involves conceptualizing problems (through algorithmic or systems thinking) and operationalizing solutions (creating, implementing, and evaluating computer-based responses to problems). The inclusion of CT as an option in ICILS 2018 reflects recent interest by educators, researchers, and policymakers in the value of CT in schooling. ICILS 2018 studied how these components of digital competence related to each other and to the school and out-of-school contexts that support learning with and about computer technology.

This report presents the outcomes at the international level of analyses of data collected in the ICILS main survey in 2018. The report aims to provide an international perspective on the ICILS data relating to CIL collected across countries. Twelve countries participated in ICILS 2018: Chile, Denmark, Finland, France, Germany, Italy, Kazakhstan, the Republic of Korea (hereafter referred to as Korea, for ease of reading), Luxembourg, Portugal, the United States, and Uruguay. The city of Moscow (Russian Federation) and the state of North Rhine-Westphalia (Germany) participated as benchmarking participants. ${ }^{1}$ Eight countries completed the CT assessment: Denmark, Finland, France, Germany, Korea, Luxembourg, Portugal, and the United States. The CT option was also completed by the state of North Rhine-Westphalia (Germany) as a benchmarking participant. This report responds to the ICILS research questions and provides observations and interpretations that may stimulate further investigation within and across countries.

\section{Purposes of ICILS 2018}

The primary purpose of ICILS 2018 was to assess the capacities of students to use ICT productively for a range of purposes, including those that go beyond a basic use of computers such as producing information products and managing digital information. Authentic computerbased assessments administered to students in their eighth year of schooling generated data that provided measures of two domains of digital competence: CIL and CT.

1 Benchmarking participants are education systems within countries. 
ICILS 2018 measured students' ability to use computers to collect and manage information and to produce and exchange information $(\mathrm{CIL})$ as well as formulate solutions to problems so that those solutions could be operationalized with a computer (CT). In ICILS 2018 the two domains are regarded to be complementary aspects of a broader notion of digital competence. ICILS 2018 assessed these domains through computer-based assessments based on real-world scenarios and problems. It investigated variations in CIL and CT across and within countries, and the relationships between each construct and student attributes (background characteristics and developed attributes), including their use and experience of computer technologies and the contexts in which CIL and CT are developed. Furthermore, using data collected from the countries that participated in the CT assessment, ICILS 2018 investigated the associations between CIL and CT.

As had been the case for ICILS 2013, ICILS 2018 also investigated the use of computers and other digital devices by students and teachers, as well as students' and teachers' attitudes toward the use of digital technologies. Some of these aspects of ICT use are potentially related to student outcomes, while others may not be directly associated with student outcomes but may inform understanding of the broad context in which digital technologies are used, including contexts both inside and outside of school in which CIL and CT are learned.

ICILS 2018 was also intended to describe variations in ICT use in order to contribute to a broader understanding of the roles of information technologies in school education. Secondary analyses of ICILS 2013 data suggested that teacher attitudes were associated with the extent to which, and the ways that, teachers used ICT in their teaching (Drossel et al. 2017a; Eickelmann and Vennemann 2017). There was also evidence that school factors, including teachers' collaborative use of ICT, contribute to shape the pedagogical use of ICT (Drossel et al. 2017b; Gerick et al. 2017).

\section{Computer and information literacy}

CIL was first measured in ICILS 2013, where it was defined as "an individual's ability to use computers to investigate, create, and communicate in order to participate effectively at home, at school, in the workplace, and in society" (Fraillon et al. 2013, p. 17). Put simply, CIL refers to a student's ability to use computer technologies to collect and manage information, and to produce and exchange information.

People's capacity to use applications on computers and other digital devices has been encompassed by various terms such as computer literacy, digital literacy, ICT literacy, and digital competence. The Organisation for Economic Co-operation and Development (OECD) framework for ICT literacy stressed the application of digital technologies to "access, manage, integrate, evaluate, and create information" (ETS [Educational Testing Service] 2002, p. 2). A review by Binkley et al. (2012) of definitions of ICT literacy concluded that they referred to abilities to access, evaluate, manage, and use information, as well as to the efficient application of technology (e.g., the effective use of applications and devices). The European Commission, as part of its DigComp project (Kluzer and Pujol Priego 2018), identified key components of digital competence. DigComp 2.0 resulted in five competence areas: information and data literacy, communication and collaboration, digital content creation, safety, and problem solving (Vuorikari et al. 2016) and DigComp 2.1 described eight proficiency levels (Carretero et al. 2017).

In the United States, the ICT sub-area measured in the Technology and Engineering Literacy assessment as part of the National Assessment of Educational Progress included proficiency with computers and software learning tools, networking systems and protocols, hand-held digital devices, and other technologies for accessing, creating, and communicating information and for facilitating creative expression. It also identified five sub-areas of competence: construction and exchange of ideas and solutions, information research, investigation of problems, acknowledgment of ideas and information, and selection and use of digital tools (US Department of Education, 
National Center for Education Statistics 2016). ICILS 2013 invoked the term CIL to emphasize that having the capacity to use the internet to search for and evaluate information was an important part of the broad capability to use modern technology (Fraillon et al. 2013).

\section{Computational thinking}

CT is the type of thinking used when programming on a computer or developing an application for another type of digital device. Fraillon et al. (2019, p. 27) defined CT as "an individual's ability to recognize aspects of real-world problems which are appropriate for computational formulation and to evaluate and develop algorithmic solutions to those problems so that the solutions could be operationalized with a computer."

CT focuses on learning foundational principles of computing. Wing (2006) regarded CT as a concept that embraces problem solving and system design, based on principles central to computer science. CT has also been described as the ways of thinking when programming a computer (Grover and Pea 2013) and can be seen as "applying tools and techniques from computer science to understand and reason about both natural and artificial systems and processes" (Royal Society 2012, p. 29). Shute et al. (2017) argued that CT is required to solve problems algorithmically (with or without the assistance of computers) by applying solutions that are reusable in different contexts. They suggested that CT involves six elements: decomposition, abstraction, algorithm design, debugging, iteration, and generalization. CT does not necessarily involve developing or implementing a formal computer code (Barr et al. 2011). However, assessments of CT are typically set in computer environments because those facilitate the capturing of the data that reflect the steps in problem solving. These steps usually involve developing or assembling instructions (often including blocks of code) that are necessary to accomplish a task (Brennan and Resnick 2012). Yadav et al. (2018, pp. 91-92) articulated the nature of CT as being focused on the processes of "abstraction, algorithms and automation."

The early stages of the introduction of computers in schools and classrooms included a focus on programming (Lockheed and Mandinach 1986). It can be argued that the links between programming and problem solving are important for educational development (Papert 1980). A key element of this in the 1980s was the educational programming language Logo, in which commands resulted in movement of a cursor or robot (termed a "turtle") on a screen, producing line graphics. Recently there has been a resurgence of interest from researchers, educators, and policymakers in the importance of CT in education (Voogt et al. 2015). Visual programming languages (where programs are created by manipulating program elements, or blocks, graphically) for children have emerged in addition to text-based programming languages (e.g., Scratch and Python) (Ortiz-Colon and Marato Romo 2016). These languages focus on the algorithmic logic underpinning coding across tasks and are considered to be accessible to novice users.

\section{Research questions}

ICILS aimed to investigate the extent of CIL and CT among grade 8 students, and the associations of these learning outcomes with student background, developed attributes, experience with using computer technologies, and learning about computer technologies. It also investigated relations between $\mathrm{CIL}$ and $\mathrm{CT}$.

\section{Computer and information literacy}

The research questions concerned with CIL remain similar to those used in ICILS 2013. The questions are framed around variations in CIL, the relationship of CIL to the characteristics of students, and the contexts in which CIL is developed. These have been articulated more fully in the ICILS 2018 assessment framework (Fraillon et al. 2019). In summary, the four research questions were the following: 
RQ CIL 1 What variations exist across and within countries in students' CIL?

RQ CIL 2 What aspects of schools and countries are related to students' CIL?

RQ CIL 3 What are the relationships between students' levels of access to, familiarity with, and self-reported proficiency in using computers and their CIL?

RQ CIL 4 What aspects of students' personal and social backgrounds (such as gender and socioeconomic background) are related to students' CIL?

Four countries participated in each of ICILS 2013 and ICILS 2018. It is possible to compare student CIL between 2013 and 2018 in the three of those counties that met the ICILS technical requirements for both cycles.

\section{Computational thinking}

The research questions relating to CT closely reflected those proposed for CIL, but excluded reference to changes from ICILS 2013 and included reference to the relationship between CT and CIL. Analyses were limited to those countries participating in the optional assessment of students' $\mathrm{CT}$ achievement. The five $\mathrm{CT}$ related research questions were the following:

RQ CT 1 What variations exist across and within countries in students' CT?

RQ CT 2 What aspects of schools and education systems are related to students' CT?

RQ CT 3 What are the relationships between students' levels of access to, familiarity with, and self-reported proficiency in using computers and their CT?

RQ CT 4 What aspects of students' personal and social backgrounds (such as gender and socioeconomic background) are related to students' CT?

RQ CT 5 What is the association between students' CIL and CT?

\section{The ICILS assessment framework}

The ICILS 2018 assessment framework provides a conceptual underpinning for the international instrumentation for ICILS (Fraillon et al. 2019). The assessment framework consists of three parts:

- The CIL framework outlines the outcome measures addressed through the CIL test.

- The CT framework outlines the outcome measures addressed through the CT test.

- The contextual framework maps the context factors expected to influence and explain variation in CIL and CT.

\section{The CIL framework}

The structure of the CIL construct references four strands that frame the skills and knowledge addressed by the CIL assessment: understanding computer use, gathering information, producing information, and digital communication. These strands define the CIL construct but are not intended to represent empirically distinct components. Each strand is further defined in terms of two aspects (Figure 1.1).

- Understanding computer use refers to the fundamental technical knowledge and skills that underpin the operational use of computers as tools for working with information. This includes a person's knowledge and understanding of the generic characteristics and functions of computers. Understanding computer use comprises two aspects: foundations of computer use and computer use conventions.

- Gathering information embraces the receptive and organizational elements of information processing and management. This subsumes two aspects: accessing and evaluating information, and managing information. 
- Producing information focuses on using computers as tools for thinking and creating. It involves two aspects: transforming information and creating information.

- Digital communication focuses on information sharing in social networking (and broader webbased information sharing spaces) together with the social, legal, and ethical responsibilities associated with information sharing and using information safely and securely.

Figure 1.1: ICILS 2018 CIL framework

Computer and information literacy refers to an individual's ability to use computers to investigate, create, and communicate in order to participate effectively at home, at school, in the workplace, and in the community.

$\begin{array}{llll} & & & \\ \text { Strand 1 } & \text { Strand 2 } & \text { Strand 3 } & \text { Strand 4 } \\ \text { Understanding } & \text { Gathering information } & \text { Producing information } & \text { Digital communication } \\ \text { computer use } & \text { Aspect 2.1 } & \text { Aspect 3.1 } & \text { Aspect 4.1 } \\ \text { Aspect 1.1 } & \text { Accessing and } & \text { Transforming } & \text { Sharing information } \\ \text { Foundations of } & \text { evaluating information } & \text { information } & \text { Aspect 4.2 } \\ \text { computer use } & \text { Aspect 2.2 } & \text { Aspect 3.2 } & \text { Using information } \\ \begin{array}{l}\text { Aspect } 1.2 \\ \text { Computer use } \\ \text { conventions }\end{array} & \text { Managing information } & \text { Creating information } & \text { responsibly and safely } \\ & & & \\ & & & \end{array}$

Source: Fraillon et al. (2019)

\section{The CT framework}

The CT construct comprises two strands: conceptualizing problems and operationalizing solutions (Figure 1.2). One strand contains three aspects and the other comprises two aspects. The aspects encompass the knowledge, skills, and understandings held in common across the range of definitions of CT.

- Conceptualizing problems acknowledges that before solutions can be developed, problems must first be understood and framed in a way that allows algorithmic or systems thinking to assist in the process of developing solutions. This strand comprises three aspects: knowing about and understanding digital systems, formulating and analyzing problems, and collecting and representing relevant data.

- Operationalizing solutions comprises the processes associated with creating, implementing, and evaluating computer-based system responses to real-world problems. It includes the iterative processes of planning for, implementing, testing, and evaluating algorithmic solutions (as the potential bases for programming) to real-world problems. The strand includes an understanding of the needs of users and their likely interaction with the system under development. This strand comprises two aspects: planning and evaluating solutions, and developing algorithms, programs, and interfaces. 
Figure 1.2: ICILS 2018 CT framework

Computational thinking refers to an individual's ability to recognize aspects of real-world problems which are appropriate for computational formulation and to evaluate and develop algorithmic solutions to those problems so that the solutions could be operationalized with a computer.

$\begin{array}{ll}\text { Strand } 1 & \text { Strand } 2 \\ \text { Conceptualizing problems } & \text { Operationalizing solutions } \\ \text { Aspect } 1.1 & \text { Aspect } 2.1 \\ \text { Knowing about and understanding digital } & \text { Planning and evaluating solutions } \\ \text { systems } & \text { Aspect } 2.2 \\ \text { Aspect } 1.2 & \text { Developing algorithms, programs, and } \\ \text { Formulating and analyzing problems } & \text { interfaces } \\ \text { Aspect } 1.3 & \\ \text { Collecting and representing relevant data } & \\ & \end{array}$

Source: Fraillon et al. (2019)

\section{The contextual framework}

ICILS 2018 collected contextual information so as to provide bases for understanding variations in CIL and CT (from here on we use CIL/CT to refer to these outcomes when common contextual information is being considered) as well as to collect data about the pedagogical use of ICT at schools. We classified the contextual factors in a framework that was consistent with the multilevel structure inherent in student CIL/CT learning and also considered these factors as antecedents or processes (Figure 1.3).

Conceptual frameworks for analyzing educational outcomes are frequently based on a multilevel structure that is inherent in student learning (Goldstein 2010; Raudenbush and Bryk 2002; Schulz 2018). Learning is set in the overlapping contexts of in-school and out-of-school learning. Out-of-school activities and experiences are important for CIL/CT learning (ACARA [Australian Curriculum, Assessment and Reporting Authority] 2015). The contextual framework of ICILS therefore embraces out-of-school learning through experience and frequency of ICT use by students outside of school (Fraillon et al. 2019).

The temporal status of contextual factors within the learning process is also important. Factors may be considered either as antecedents or processes. Antecedents are exogenous factors that condition the ways in which CIL/CT learning takes place. They are contextual factors that are not directly influenced by learning-process variables or outcomes. It is important to recognize that antecedent variables are level-specific and may be influenced by antecedents and processes found at higher levels, for example, the extent to which schools' ICT resources are likely to be influenced by ICT education policies at the level of the education system. Processes are those factors that directly influence CIL/CT learning. They are constrained by antecedent factors and factors found at higher levels. These antecedent factors could include variables such as opportunities for CIL/CT learning during class, teacher attitudes toward using ICT for study tasks, and students' use of computers at home. 
Figure 1.3: Contexts for ICILS 2018 CIL/CT outcomes

\section{Antecedents}

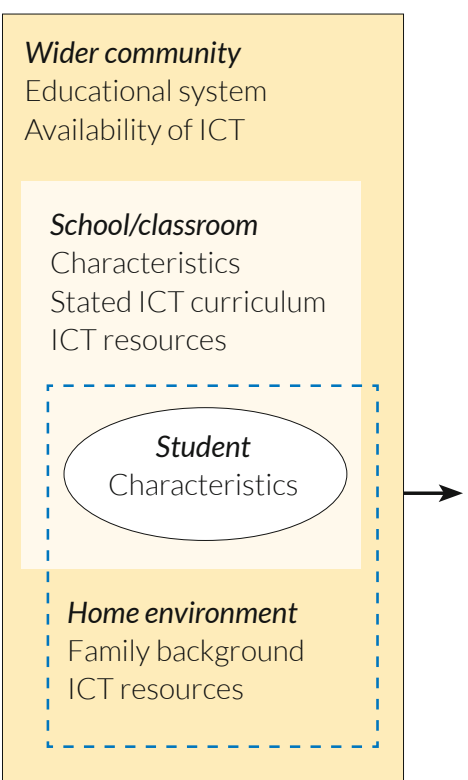

\section{Processes}

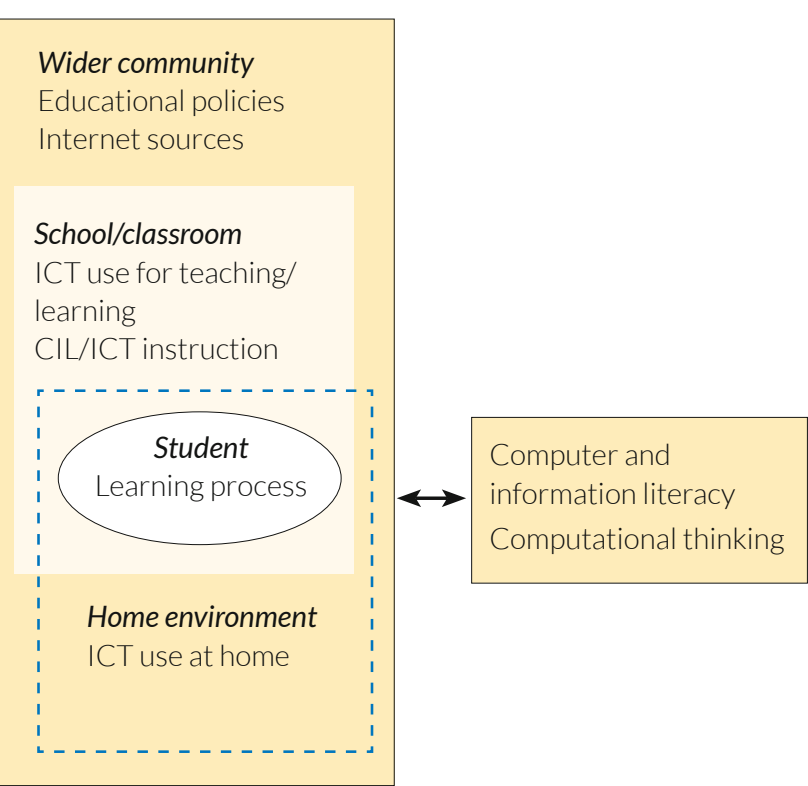

Notes: The double arrow between process-related factors and outcomes emphasizes the possibility of a reciprocal association between learning processes and learning outcomes. The single-headed arrow between antecedents and processes indicates the assumption within the ICILS contextual framework of a unidirectional influence between these two types of contextual factors.

Source: Fraillon et al. (2019).

Reference to this general conceptual framework enabled us to locate potential contextual factors on a two-by-four grid where antecedents and processes constitute the columns and the four levels the rows (Table 1.1 provides examples of the contextual variables collected by the ICILS instruments).

Table 1.1: Mapping of variables to the contextual framework related to CIL and CT outcomes (examples)

\begin{tabular}{|c|c|c|c|}
\hline Level of ... & Analysis level & Antecedents & Processes \\
\hline Wider community & $\begin{array}{l}\text { Not used in } \\
\text { within-country } \\
\text { multilevel analyses }\end{array}$ & $\begin{array}{l}\text { NCS \& other sources: } \\
\text { Structure of education } \\
\text { Accessibility of ICT }\end{array}$ & $\begin{array}{l}\text { NCS \& other sources: } \\
\text { Role of ICT in curriculum }\end{array}$ \\
\hline School/classroom & School level & $\begin{array}{l}\text { PrQ, ICQ, \& TQ: } \\
\text { School characteristics } \\
\text { ICT resources }\end{array}$ & $\begin{array}{l}\text { PrQ, ICQ, TQ, \& StQ: } \\
\text { ICT use in teaching } \\
\text { and learning } \\
\text { CIL/CT instruction }\end{array}$ \\
\hline Student & Student level & $\begin{array}{l}\text { StQ: } \\
\text { Gender } \\
\text { Age } \\
\text { ICT experience }\end{array}$ & $\begin{array}{l}\text { StQ: } \\
\text { ICT activities } \\
\text { Use of ICT } \\
\text { CIL/CT }\end{array}$ \\
\hline Home environment & & $\begin{array}{l}\text { StQ: } \\
\text { Parent socioeconomic } \\
\text { status } \\
\text { Home ICT resources }\end{array}$ & $\begin{array}{l}\text { StQ: } \\
\text { Learning about ICT } \\
\text { at home }\end{array}$ \\
\hline
\end{tabular}

Note: NCS = national contexts survey; $\mathrm{PrQ}$ = principal questionnaire; ICQ = ICT coordinator questionnaire; TQ = teacher questionnaire; $\mathrm{StQ}=$ student questionnaire. 
The student questionnaire collected data on contextual factors pertaining to the level of the individual student and their home context. The teacher, school principal, and ICT coordinator questionnaires were designed to gather information about contextual factors associated with the school/classroom level. In addition, and separate from the multilevel analyses, the national contexts survey (NCS) and other available sources (e.g., published statistics), provided national contextual data that facilitated interpretation.

\section{ICILS instruments}

In total, ICILS collected data using six instruments (seven in countries that participated in the CT assessment). Students completed the test of CIL, a questionnaire, and (where applicable) the test of CT. Separate questionnaires were completed by teachers, school ICT coordinators, school principals, and staff in national research centers.

The ICILS 2018 assessments of students' CIL and CT were designed to provide students with an authentic computer-based assessment experience in a uniform way. ICILS 2018 used a customized assessment platform that delivered the assessment content to students offline. In the majority of schools the assessments were delivered from a USB drive. A few schools installed the materials on a computer that functioned as a server for a network of school computers. The instrument used purpose-built applications that followed standard interface conventions. Students completed a range of tasks including skills-based tasks using productivity software tools (such as text editors or presentation applications) and web-content. The purpose-built applications were designed to be consistent with the applications that could reasonably be expected to be within the realm of students' typical experience of computer use.

\section{CIL test design}

The CIL assessment tasks were embedded within modules. In total, there were five 30-minute CIL modules. Each student completed two of the five CIL modules. The CIL modules were allocated to students in a balanced randomized design.

Each CIL module comprised a sequence of tasks contextualized by a real-world theme and driven by a plausible narrative. Each module included a series of five to eight smaller tasks, each of which typically took students less than one minute to complete, and each of which contributed to the development of contextual knowledge that underpinned work on a single large task. The large tasks typically took 15 to 20 minutes to complete and involved the development of an information product (such as a presentation, poster, website, or social media post) that made use of information and resources managed by students in the lead-up tasks. The large tasks were specified for students in terms of the software tools and format to be used (and consequently the format of the product), the communicative purpose, and the target audience of the information product.

Three of the CIL modules had been developed and used in ICILS 2013 and kept secure. Two new modules were developed for the ICILS 2018 CIL test instrument to address contemporary thematic content and software environments. Data collected from all five CIL modules in ICILS 2018 were used as the basis for reporting ICILS 2018 CIL results on the ICILS CIL achievement scale established in 2013. The rotated module design enabled the instrument to contain, and consequently report on achievement against, a larger amount of content (covering the breadth of the CIL framework and a range of difficulties) than any single student could reasonably complete in 60 minutes. 


\section{CT test design}

Two 25-minute CT modules were developed for the ICILS 2018 CT assessment: one on conceptualizing problems and the other on operationalizing solutions. Each had a unifying theme and a sequence of tasks that related to the theme (but not a large task).

The tasks in the CT module focusing on conceptualizing problems related to planning aspects of a program to operate a driverless bus. This included visual representation of real-world situations in ways that could support the development of computer programs to execute automated solutions (e.g., path diagrams, flow charts, and decision trees). Further tasks related to the use of simulations to collect data and draw conclusions about real-world situations that could inform planning the development of a computer program.

In the CT module focusing on operationalizing solutions, students worked within a simple visual coding environment to create, test, and debug code (blocks of code that have some specified and some configurable functions) that controlled the actions of a drone used in a farming context. In this module, the tasks were incrementally more complex as the students advanced through the module. The complexity of the tasks related to the variety of code functions that were available and the sequence of actions required by the drone for completion of the task.

In countries participating in the ICILS 2018 CT option, students completed both CT modules after having finished both the CIL assessment and the student questionnaire.

\section{International student questionnaire}

A 30-minute international student questionnaire was completed on computer by students following completion of the CIL assessment. It included questions relating to students' background characteristics, their experience and use of computers and ICT to complete a range of different tasks in school and out of school, and their attitudes towards the use of computers and ICT.

\section{Teacher and school questionnaires}

Three instruments were designed to gather information from and about teachers and schools. These instruments could be completed on computer (over the internet) or on paper depending on the availability of resources in schools and countries. These instruments were:

- A 30-minute teacher questionnaire: A teacher questionnaire was designed to be completed by a random sample of 15 teachers of grade 8 students. A consequence of this approach to sampling was that the data could be used to generate school and system-level aggregates but that they could not be linked to individual students. The questionnaire asked about teacher background including familiarity with ICT, their use of ICT in educational activities in teaching focused on a randomly-selected reference class, teachers' perceptions of ICT in schools, and learning to use ICT in teaching.

- A 15-minute ICT coordinator questionnaire: A questionnaire to be completed by ICT coordinators asked about ICT resources in the school (computers, other devices, digital learning resources, networking and internet connectivity), ICT use in the school (provision for specialist teaching of ICT, emphasis in curriculum areas, learning management systems, school administration), ICT technical support (maintenance provision, support for managing resources), and provisions for professional development in ICT at school.

- A 15-minute principal questionnaire: A questionnaire completed by school principals provided information about school characteristics and policies, procedures, and priorities for ICT at the sampled school. 


\section{National coordinator questionnaires}

ICILS 2018 national research coordinators provided information, based on the input of national experts, in response to an online NCS. Data from the NCS were used for comparing profiles of $\mathrm{CIL}$ and $\mathrm{CT}$ education in participating countries. The NCS provided data on contextual factors concerned with structure of the education system and systematic descriptions of policy and practice in the use of ICT in school education. The data provided the bases for analyses of the influence of system-level contexts on differences in CIL/CT learning, and for interpreting differences among countries in the patterns of relationships among factors that are related to CIL/CT learning.

\section{Participating countries, population, sample design, and achieved samples}

\section{Countries or education systems}

Twelve countries and two benchmarking participants participated in ICILS 2018.

Countries participating in ICILS 2018

- Chile (CIL)

- $\operatorname{Denmark}(\mathrm{CI}$ and CT)

- Finland (CIL and CT)

- France (CIL and CT)

- Germany (CIL and CT)

- Italy (CIL)

Benchmarking participants

- Moscow (Russian Federation) (CIL)
- Kazakhstan (CIL)

- Korea (CIL and CT)

- Luxembourg (CIL and CT)

- Portugal (CIL and CT)

- The United States (CIL and CT)

- Uruguay (CIL)

- North Rhine-Westphalia (Germany) (CIL and CT)

Benchmarking participants are education systems within countries. In ICILS 2018, the city of Moscow in the Russian Federation took part as a benchmarking participant even though the country did not participate. In contrast, the German state of North Rhine-Westphalia took part as a benchmarking participant in addition to the participation of the country of Germany. Additional schools were sampled in North Rhine-Westphalia to enable accurate reporting of data representing that entity. Data collected from North Rhine-Westphalia also contributed to the data reported for Germany as a whole.

Data collected from benchmarking participants were not included in the establishment of reporting scales, nor were they included in the computation of international averages. However, data from a benchmarking participant may be compared to the international data if the benchmarking participant has satisfied the technical requirements of the study. Both the city of Moscow (Russian Federation) and North Rhine-Westphalia (Germany) met the technical requirements of ICILS 2018.

\section{Administration periods}

The ICILS 2018 main survey data collection took place in the first half of 2018 for participants in the Northern Hemisphere ${ }^{2}$ and in the second half of 2018 for participants in the Southern Hemisphere. ${ }^{3}$ In Italy the survey data collection took place in the second half of 2018 (i.e., the beginning of the school year) even though it was a Northern Hemisphere participant.

2 The Northern Hemisphere participants were: Denmark, Finland, France, Germany, Italy, Kazakhstan, Korea, Luxembourg, Portugal, the United States, Moscow (Russian Federation), and North Rhine-Westphalia (Germany).

3 The Southern Hemisphere participants were Chile and Uruguay. 


\section{Population definitions}

The ICILS student population was defined as students in grade 8 (typically around 14 years of age in most countries), provided that the average age of students in this grade was at least 13.5 years at the time of the assessment.

The population for the ICILS teacher survey was defined as consisting of all teachers teaching regular school subjects to the students in the target grade at each sampled school. It included only those teachers who were teaching the target grade during the testing period and who had been employed at the school since the beginning of the school year. ICILS also administered separate questionnaires to principals and nominated ICT coordinators in each school.

\section{Sample design}

\section{Schools}

The samples were designed as two-stage cluster samples. During the first stage of sampling, schools with enrolled students at the target grade were randomly selected with a probability proportional to size as measured by the number of students enrolled in a school. The numbers required in the sample to achieve the necessary precision were estimated on the basis of national characteristics. However, as a guide, each country was instructed to plan for a minimum sample size of 150 schools except in very small education systems where all schools were included in the survey. The schools sampled at the first stage were then used to select both students and teachers. The numbers of schools in the achieved samples in each country or benchmarking participant ranged between 35 (in a very small system, with next smallest sample being 110) and 261.

\section{Students}

Within each participating school, 20 students were randomly sampled from all students enrolled in the target grade. In schools with fewer than 20 students, all students were invited to participate.

\section{Teachers}

Fifteen teachers were selected at random from all teachers teaching the target grade at each sampled school. In schools with 20 or fewer such teachers, all teachers were invited to participate. Because of the intention that teacher information should not be linked to individual students, all teachers of the target grade were eligible to be sampled regardless of the subjects they taught.

\section{Participation requirements and reporting}

The participation rates required for each country were 85 percent of the selected schools and 85 percent of the selected students within the participating schools, or a weighted overall participation rate of 75 percent. The same criteria were applied to the teacher sample, but the coverage was judged independently of those for the student sample.

In the tables in this report, we use annotations to identify those countries that met these response rates only after using replacement schools. Countries that did not meet the response rates, even after replacement, are reported separately below the main section of each table. Results from education systems that took part as benchmarking participants also appear as a further separate section in the tables of this report. (Appendix A documents sampling information and participation rates for each country.)

\section{Achieved samples}

ICILS 2018 gathered data from 46,561 grade 8 (or equivalent) students in 2226 schools from 12 countries and two benchmarking participants. These student data were augmented by data from 26,530 teachers in those schools and by contextual data collected from school ICT coordinators, principals, and national research centers. 
The average student participation rate (after replacement procedures) achieved was 87 percent. Eleven of the 12 participating countries and both benchmarking participants satisfied or nearly satisfied the required participation rate for students and are reported in the main section of the reporting tables. Italy assessed its grade 8 students at the beginning of the school year and therefore the average age of sampled students is lower than 13.5 years at the time of assessment which is below target group population age defined for the survey. As a consequence, CIL results from Italy are reported separately in the tables in Chapter 3 to indicate to readers that results from this country are not entirely comparable with other countries.

The average teacher participation rate (after replacement procedures) was 82 percent. Seven of the 12 participating countries and both benchmarking participants satisfied the required participation rate for teachers.

\section{Structure of this report}

The six chapters following this present and discuss analyses of the ICILS data and serve to address the ICILS research questions. The last chapter (Chapter 8 ) concludes the report with reflections on the themes that are evident across ICILS 2018 and on future directions for research.

Chapter 2 describes the national contexts for CIL and CT education in ICILS 2018 countries. It addresses common patterns as well as policies, curriculum, resources, and practices in specific countries and groups of countries.

Chapter 3 reports on CIL proficiency across countries. It describes how the student test was used to measure CIL and presents the ICILS scale of CIL proficiency. The chapter then documents how student achievement on the CIL scale varied across and within participating countries. It examines gender differences in CIL and variations in CIL related to socioeconomic background, immigrant status, and home ICT resources. For three countries it was possible to report on changes in CIL between 2013 and 2018.

Chapter 4 reports on CT proficiency across countries. It describes the nature of the CT tests and the achievement scale that was derived from the assessment data. It documents how CT achievement varied across and within participating countries and the how variations related to gender, socioeconomic background, immigrant status, and home ICT resources. It also reports on the association between CIL and CT.

Chapter 5 explores students' use of, and engagement with, ICT at home and school. Data reported on in this chapter were collected using the student questionnaire. Standardized scale indices are used to report students' use of ICT for a range of purposes and ICT-related attitudes. The chapter also reports on differences between male and female students as well as differences in use across subject areas, and associations of self-perceptions with CIL/CT achievement.

The focus of Chapter 6 is teaching with and about ICT, specifically on the roles of schools in $\mathrm{CIL/CT}$ education. This chapter is based on data from the teacher, ICT coordinator, and principal questionnaires and describes the variation in approaches to the provision of CIL/CT related education in schools. It reviews teacher familiarity with ICT, teacher confidence in using ICT, teacher views about using ICT in education, and the ICT tools that they use in teaching activities. It reports on the emphasis teachers place on developing CIL/CT, as well as on the pedagogical use of ICT, and associations between these emphases and teacher attributes.

Chapter 7 presents the outcomes of multivariate and multilevel models used to explain variations in CIL/CT within countries. The models incorporate student-level and school-level influences explaining variation in $\mathrm{CIL}$ and $\mathrm{CT}$ outcomes. 
Chapter 8 discusses the themes emerging from the results of ICILS 2018. We reflect on the key findings relating to student achievement in $\mathrm{CIL}$ and $\mathrm{CT}$, the digital divide and student gender, and on the use of ICT in schools and teaching. The chapter includes reflections on implications of the results for policy and practice and suggests some directions for future research on CIL and CT.

\section{References}

ACARA. (2015). National Assessment Program - ICT literacy years $6 \& 102014$ report. Sydney, Australia: Australian Curriculum, Assessment and Reporting Authority. Retrieved from http://www.nap.edu. au/_resources/D15_8761_NAP-ICT_2014_Public_Report_Final.pdf.

Barr, D., Harrison, J., \& Conery, L. (2011). Computational thinking: A digital age skill for everyone. Learning \& Leading with Technology, 38(6), 20-23. Retrieved from https://id.iste.org/docs/learning-and-leadingdocs/march-2011-computational-thinking-II386.pdf.

Binkley, M., Erstad, E., Herman, J., Raizen, S., Ripley, M., Miller-Ricci, M., \& Rumble, M. (2012). Defining 21st century skills. In P. Griffin, B. McGaw, \& E. Care (Eds.), Assessment and teaching of 21st century skills (pp. 17-66). Dordrecht, The Netherlands: Springer. Retrieved from https://link.springer.com/chapter/1 0.1007\%2F978-94-007-2324-5_2.

Brennan, K., \& Resnick, M. (2012). New frameworks for studying and assessing the development of computational thinking. Paper presented at the 2012 Annual Meeting of the American Educational Research Association, Vancouver, Canada. Retrieved from https://web.media.mit.edu/ kbrennan/files/ Brennan_Resnick_AERA2012_CT.pdf.

Carretero, S., Vuorikari, R., \& Punie, Y. (2017). DigComp 2.1: The Digital Competence Framework for Citizens with eight proficiency levels and examples of use. Joint Research Centre Report EUR 28558 EN. Luxembourg: Publication Office of the European Union. Retrieved from https://doi.org/10.2760/38842.

Chalkiadaki, A. (2018). A systematic literature review of 21st century skills and competencies in primary education. International Journal of Instruction, 11(3), 1-16. Retrieved from http://www.e-iji.net/dosyalar/ iji_2018_3_1.pdf.

Drossel, K., Eickelmann, B., \& Gerick, J. (2017a). Predictors of teachers' use of ICT in school - the relevance of school characteristics, teachers' attitudes and teacher collaboration. Education and Information Technologies, 22(2), 551-573. Retrieved from https://link.springer.com/article/10.1007\%2Fs10639-0169476-y.

Drossel, K., Eickelmann, B., \& Schulz-Zander, R. (2017b). Determinants of teachers' collaborative use of ICT for teaching and learning: a European perspective. European Educational Research Journal, 16(6), 781-799. Retrieved from https://doi.org/10.1177\%2F1474904116655811.

ETS. (2002). Digital transformation: A framework for ICT literacy. Princeton, NJ: Educational Testing Service. Retrieved from http://www.ets.org/Media/Research/pdf/ICTREPORT.pdf.

Eickelmann, B., \& Vennemann, M. (2017). Teachers' attitudes and beliefs towards ICT in teaching and learning in European countries. European Educational Research Journal, 16(6), 1-29. Retrieved from https:// doi.org/10.1177\%2F1474904117725899.

Fraillon, J., Ainley, J., Schulz, W., Duckworth, D., \& Friedman, T. (2019). IEA International Computer and Information Literacy Study 2018 assessment framework. Cham, Switzerland: Springer. Retrieved from https:// www.springer.com/gp/book/9783030193881.

Fraillon, J., Ainley, J., Schulz, W., Friedman, T., \& Gebhardt, E. (2014). Preparing for life in a digital age: The IEA International Computer and Information Literacy Study international report. Cham, Switzerland: Springer. Retrieved from https://www.springer.com/gp/book/9783319142210.

Fraillon, J., Schulz, W., \& Ainley, J. (2013). International Computer and Information Literacy Study assessment framework. Amsterdam, The Netherlands: International Association for the Evaluation of Educational Achievement (IEA). Retrieved from https://www.iea.nl/publications/assessment-framework/internationalcomputer-and-information-literacy-study-2013.

Gerick, J., Eickelmann, B., \& Bos, W. (2017). School-level predictors for the use of ICT in schools and students' CIL in international comparison. Large-scale Assessments in Education, 5(1), 1-13. Retrieved from https:/doi.org/10.1186/s40536-017-0037-7.

Goldstein, H. (2010). Multilevel statistical models (4th ed.). Hoboken, NJ: John Wiley and Sons. 
Grover, S., \& Pea, R. (2013). Computational thinking in K-12: A review of the state of the field. Educational Researcher, 42(1), 38-43.

Kluzer, S., \& Pujol Priego, L. (2018). DigComp into action: Get inspired, make it happen. In S. Carretero, Y. Punie, R. Vuorikari, M. Cabrera, \& W. O'Keefe (Eds.), JRC Science for Policy Report, EUR 29115 EN. Luxembourg: Publications Office of the European Union. Retrieved from http://publications.jrc.ec.europa. eu/repository/bitstream/JRC110624/dc_guide_may18.pdf.

Lockheed, M., \& Mandinach, E. B. (1986). Trends in educational computing: decreasing interest and the changing focus of instruction. Educational Researcher, 15(5), 21-26.

Ortiz-Colon, A. M., \& Marato Romo, J. L. (2016). Teaching with Scratch in compulsory secondary education. International Journal of Emerging Technologies in Learning, 11(2), 67-70. Retrieved from https://onlinejournals.org/index.php/i-jet/article/view/5094.

Papert, S. (1980). Mindstorms: Children, computers, and powerful ideas. New York, NY: Basic Books.

Raudenbush, S., \& Bryk, A. (2002). Hierarchical linear models: Applications and data analysis methods. Thousand Oaks, CA: Sage.

Royal Society. (2012). Shutdown or restart: The way forward for computing in UK schools. London, UK: Author. Retrieved from https://royalsociety.org/-/media/education/computing-in-schools/2012-01-12computing-in-schools.pdf.

Schulz, W. (2018). The reporting of ICCS 2016 results. In W. Schulz, R. Carstens, B. Losito, \& J. Fraillon (Eds.), ICCS 2016 technical report. Amsterdam, The Netherlands: International Association for the Evaluation of Educational Achievement (IEA).

Shute, V. J., Sun, C., \& Asbell-Clarke, J. (2017). Demystifying computational thinking. Educational Research Review, 22(1), 142-158. Retrieved from https://www.learntechlib.org/p/204418/.

US Department of Education, National Center for Education Statistics. (2016). The nation's report card: 2014 Technology \& Engineering Literacy (TEL) report card at grade 8. Report number NCES2016119. Washington, DC: Author. Retrieved from https://www.nationsreportcard.gov/tel_2014/.

Van Laar, E., van Deursen, A.J.A.M., van Dijk, J.A.G.M., \& de Haan, J. (2017). The relation between 21stcentury skills and digital skills: A systematic literature review. Computers in Human Behavior, 72, 577-588. Retrieved from https://doi.org/10.1016/j.chb.2017.03.010.

Vuorikari, R., Punie, Y., Carretero Gomez, S., \& van den Brande, G. (2016). DigComp 2.0: The digital competence framework for citizens. Update phase 1: The conceptual reference model. Joint Research Centre Report EUR 27948 EN. Luxembourg: Publication Office of the European Union. Retrieved from https:// doi.org/10.2791/11517

Voogt, J., Fisser, P., Good, J., Mishra, P., \& Yadav, A. (2015). Computational thinking in compulsory education: Towards an agenda for research and practice. Education and Information Technologies, 20(4), 715-728. Retrieved from https://link.springer.com/article/10.1007/s10639-015-9412-6.

Wing, J.M. (2006). Computational thinking. Communications of the ACM, 49(3), 33-35. Retrieved from https://doi.org/10.1145/1118178.1118215.

Yadav, A., Sands, P., Good, J., \& Lishinki, A. (2018). Computer science and computational thinking in the curriculum: Research and practice. In J. Voogt., G. Knezek, R. Christensen, \& K.W. Lai (Eds.), Second handbook of information technology in primary and secondary education. Cham, Switzerland: Springer. Retrieved from https://www.springer.com/gp/book/9783319710532.

Open Access This chapter is licensed under the terms of the Creative Commons Attribution-NonCommercial 4.0 International License (http://creativecommons.org/licenses/by-nc/4.0/), which permits any noncommercial use, sharing, adaptation, distribution and reproduction in any medium or format, as long as you give appropriate credit to the original author(s) and the source, provide a link to the Creative Commons license and indicate if changes were made.

The images or other third party material in this chapter are included in the chapter's Creative Commons license, unless indicated otherwise in a credit line to the material. If material is not included in the chapter's Creative Commons license and your intended use is not permitted by statutory regulation or exceeds the permitted use, you will need to obtain permission directly from the copyright holder. 